\title{
Advanced Therapeutic Gastrointestinal Endoscopy in Children - Today and Tomorrow
}

\author{
Zaheer Nabi and Duvvur Nageshwar Reddy \\ Department of Gastroenterology, Asian Institute of Gastroenterology, Hyderabad, Telangana, India
}

Gastrointestinal (GI) endoscopy plays an indispensable role in the diagnosis and management of various pediatric GI disorders. While the pace of development of pediatric GI endoscopy has increased over the years, it remains sluggish compared to the advancements in GI endoscopic interventions available in adults. The predominant reasons that explain this observation include lack of formal training courses in advanced pediatric GI interventions, economic constraints in establishing a pediatric endoscopy unit, and unavailability of pediatric-specific devices and accessories. However, the situation is changing and more pediatric GI specialists are now performing complex GI procedures such as endoscopic retrograde cholangiopancreatography and endoscopic ultrasonography for various pancreatico-biliary diseases and more recently, per-oral endoscopic myotomy for achalasia cardia. Endoscopic procedures are associated with reduced morbidity and mortality compared to open surgery for GI disorders. Notable examples include chronic pancreatitis, pancreatic fluid collections, various biliary diseases, and achalasia cardia for which previously open surgery was the treatment modality of choice. A solid body of evidence supports the safety and efficacy of endoscopic management in adults. However, additions continue to be made to literature describing the pediatric population. An important consideration in children includes size of children, which in turn determines the selection of endoscopes and type of sedation that can be used for the procedure. Clin Endosc 2018;51:142-149

Key Words: Endoscopy, gastrointestinal; Cholangiopancreatography, endoscopic retrograde; Esophageal achalasia; Pancreatic diseases

\section{INTRODUCTION}

Pediatric endoscopy is being performed over several decades and is an important diagnostic and therapeutic modality in the management of various pediatric gastrointestinal (GI) disorders. A major constraint for the development of endoscopy in children was unavailability of scopes of the desired size, inadequate expertise of pediatric gastroenterologists in performing advanced endoscopic procedures, and economic constraints in developing a dedicated endoscopy unit for chil-

Received: June 16, 2017 Revised: September 2, 2017

Accepted: September 9, 2017

Correspondence: Duvvur Nageshwar Reddy

Department of Gastroenterology, Asian Institute of Gastroenterology, 6-3-661, Somajiguda, Hyderabad, Telangana 500082, India

Tel: +91-40-2337-8888, Fax: +91-40-2332-4255, E-mail: aigindia@yahoo.co.in ORCID: https://orcid.org/0000-0001-7540-0496

cc This is an Open Access article distributed under the terms of the Creative Commons Attribution Non-Commercial License (http://creativecommons.org/ licenses/by-nc/3.0) which permits unrestricted non-commercial use, distribution, and reproduction in any medium, provided the original work is properly cited. dren. Adult duodenoscopes used for endoscopic retrograde cholangiopancreatography (ERCP) and echoendoscopes used for endoscopic ultrasonography (EUS) have diameters that may compress the soft airways of young children. With the availability of pediatric scopes, diagnostic and therapeutic endoscopy has become easier and safer in infants and smaller children. The primary constraint with use of pediatric scopes is the smaller size/diameter of working channels, which may not allow the passage of many useful accessories.

Another significant barrier in the growth of pediatric GI endoscopy includes economic constraints, which may hamper the establishment of a dedicated endoscopy suite for children, and a majority of centers utilize endoscopy suites, which have been designed for adults. Moreover, advanced therapeutic procedures are less commonly performed in pediatric patients compared to adults, further emphasizing the cost-issues of setting up a pediatric endoscopy unit.

The need for advanced GI endoscopic procedures cannot be underestimated in pediatric patients. These procedures po- 
tentially minimize morbidities associated with several surgical procedures and are useful in diseases such as chronic pancreatitis, pancreatic fluid collections (PFCs), and achalasia cardia (AC).

Our subsequent discussion will focus on recent advancements in state-of-the-art therapeutic GI endoscopic procedures in the pediatric population.

\section{PRE-PROCEDURAL CONSIDERATIONS IN CHILDREN - SEDATION AND SCOPES}

There are two unique issues that demand attention prior to considering any endoscopic intervention in children. The first issue is selection of scopes and the second is type of sedation to be used. Unlike in adults, the selection of various endoscopes is based on the size of children. Similarly, a significant proportion of children require general anesthesia in contrast to adults where most therapeutic endoscopic procedures can be performed under conscious sedation or deep sedation.

With the availability of pediatric duodenoscopes (outer diameter of $7.5 \mathrm{~mm}$ ), the size of children usually does not hinder successful outcomes of an ERCP performed in children. Several studies describe the successful use of adult duodenoscopes (outer diameter of 11.3-11.6 mm) in children. A primary advantage associated with use of an adult duodenoscope is its wider channel (up to $4.2 \mathrm{~mm}$ ), which allows the use of accessories that might not be compatible with pediatric duodenoscopes. Pediatric duodenoscopes (outer diameter of 7.5 $\mathrm{mm}$ ) do not allow passage of triple lumen sphincterotomes and stents larger than 5 Fr. The guidelines established by the European Society of Gastroenterology (ESGE) and the European Society for Paediatric Gastroenterology Hepatology and Nutrition (ESPGHAN) recommend pediatric duodenoscopes with an outer diameter of $7.5 \mathrm{~mm}$ for children weighing $<10$ $\mathrm{kg}$ and adult duodenoscopes in those weighing $>10 \mathrm{~kg}$. ${ }^{1,2}$

With regard to EUS, commercially available EUS scopes (outer diameter of 11-14 mm) limit the use of EUS in infants and small children. Additionally, the stiff distal tip of the scope increases the risk of cervical esophageal perforation. ESGE/ ESPGHAN guidelines recommend the use of endobronchial ultrasonography in children weighing $<15 \mathrm{~kg}{ }^{3}$

The second issue is the type of sedation used to perform endoscopic procedures in children. Advanced therapeutic procedures like ERCP and EUS may have an unpredictably long procedure time. Additionally, small children and infants have soft airways and therefore present a higher risk of compression by scopes. The risk of hypoxia is further exacerbated by the prone position, which is often used during an ERCP. The recently published ESGE/ESPGHAN guidelines suggest use of general anesthesia with tracheal intubation for an ERCP or EUS performed in children. Deep/conscious sedation without tracheal intubation may be considered for children $>12$ years of age. ${ }^{2}$

Table 1. Selected Studies Describing the Results of Endoscopic Retrograde Cholangiopancreatography in Children

\begin{tabular}{|c|c|c|c|c|c|}
\hline Study & $n$ & $\begin{array}{c}\text { Mean age } \\
(y r)\end{array}$ & $\begin{array}{c}\text { Scope used } \\
\text { (outer diameter, } \mathrm{mm} \text { ) }\end{array}$ & $\begin{array}{l}\text { Success } \\
(\%)\end{array}$ & $\begin{array}{c}\text { Complications } \\
\text { (\%) }\end{array}$ \\
\hline Varadarajulu et al. $(2004)^{4}$ & 116 & 9.3 & $\begin{array}{l}\text { JF-100/130 (11) } \\
\text { TJF-100/130/140 (12.5) } \\
\text { JPF (7.5) }\end{array}$ & 97.5 & 3.4 \\
\hline Cheng et al. $(2005)^{5}$ & 245 & 12.3 & $\begin{array}{l}\text { PJF (7.5) } \\
\text { JF (10.5) } \\
\text { TJF-100 (12.5) }\end{array}$ & 97.9 & 9.7 \\
\hline Issa et al. $(2007)^{6}$ & 125 & 13.25 & JF1 T20 (11) & 96.8 & 3.2 \\
\hline Dua et al. $(2008)^{7}$ & 185 & - & $\begin{array}{l}\text { Adult duodenoscope }(11 / 12.5) \\
\text { JPF (7.5) }\end{array}$ & 98 & 2.1 \\
\hline Otto et al. $(2011)^{8}$ & 167 & 11.4 & - & - & 4.76 \\
\hline Enestvedt et al. $(2013)^{9}$ & 296 & 14.9 & - & 95.2 & 17.5 \\
\hline Agarwal et al. $(2014)^{10}$ & 172 & 13.8 & JF145/160/180 (11.2-12.5) & - & 4.7 \\
\hline Saito et al. $(2014)^{11}$ & 220 & 4 & $\begin{array}{l}\text { XPJF }(7.5 / 8.5 / 8.8) \\
\text { PJF 7.5/240 }(7.5,7.7) \\
\text { JF 200/ 230/ 240/ } 260(12.0,12.6)\end{array}$ & 96 & 9.8 \\
\hline Giefer et al. $(2015)^{12}$ & 276 & 13.6 & $\begin{array}{l}\text { TJF-Q180V (11.3) } \\
\text { PJF-160 (7.5) }\end{array}$ & 95 & 19.6 \\
\hline Rosen et al. $(2017)^{13}$ & 215 & 14 (median) & $\begin{array}{l}\text { TJF-160 (11.3) } \\
\text { JF-140F (11) }\end{array}$ & 97 & 10 \\
\hline
\end{tabular}




\section{ENDOSCOPIC RETROGRADE CHOLANGIOPANCREATOGRAPHY IN CHILDREN}

The procedure of ERCP has increased manifolds over the last few decades in children. An increasing body of evidence supports the safety and efficacy of ERCP in children (Table 1). ${ }^{4-13}$ An ERCP is performed in children primarily for pancreatico-biliary indications such as biliary obstruction, chronic pancreatitis, recurrent acute pancreatitis, choledochal cysts, trauma, and sphincter of Oddi dysfunction. The therapeutic success of ERCP in large pediatric case series was demonstrated to be $>90 \%$ with a complication rate of approximately $5 \%-10 \%$. Therefore, the efficacy and safety rates of an ERCP performed in children are comparable to adults.

The most convincing evidence of the efficacy of ERCP exists with respect to chronic pancreatitis in children. ${ }^{10,14} \mathrm{~A}$ recent study has revealed that complete and partial pain relief was achieved in $63.6 \%$ and $21.6 \%$ of children, respectively after endotherapy was performed. ${ }^{10}$ Extracorporeal shock wave lithotripsy (ESWL) has also been shown to be safe and effective in children with pancreatic ductal calculi (Fig. 1). ESWL is usually performed for large pancreatic ductal calculi $(\geq 5 \mathrm{~mm}$ ). Complete clearance of calculi was achieved in $86 \%$ of children in whom ERCP was performed after an ESWL. ${ }^{15}$ Mild post-ERCP pancreatitis was the most common adverse event observed after the ESWL procedure.

The safety of ERCP has been evaluated in several recent studies. ${ }^{10,16,17}$ A recent systematic review and meta-analysis has shown a pooled complication rate of $6 \%$ ( $95 \%$ confidence interval $4 \%-8 \%$ ) including post-ERCP pancreatitis (4.7\%), bleeding $(0.6 \%)$, and infections $(0.8 \%){ }^{17}$ The risk factors for post-ERCP pancreatitis in children include injection of contrast into the pancreatic duct and pancreatic sphincterotomy. ${ }^{18}$ Cho et al., analyzed the adverse events and long-term outcomes associated with an endoscopic sphincterotomy in a pediatric population. ${ }^{16}$ In this retrospective study, early adverse events ( $<30$ days) included pancreatitis (5.7\%), bleeding $(2.0 \%)$, sepsis $(1.0 \%)$, and perforations $(0.7 \%)$. Long-term adverse events ( $>30$ days) including cholangitis and minor papilla restenosis were noticed in $6.1 \%$ of children. ${ }^{16}$ Post-ERCP pancreatitis is the most common adverse event as mentioned above. Unlike adults, there are no studies specifically addressing this issue, and strategies to prevent post-ERCP pancreatitis are unclear in children. However, expert guidelines from ESPGHAN and ESGE recommend the use of nonsteroidal anti-inflammatory drugs such as diclofenac/indomethacin suppositories for the prophylaxis of post-ERCP pancreatitis in children older than 14 years. ${ }^{2}$ There appears to be significant heterogeneity in published literature with respect to the reported prevalence of adverse events. This may be due to differences in types of cases, operator's experience, and the definition used to describe adverse events. Unfortunately, there is no accepted definition to grade the severity of adverse events in the pediatric population. This is in contrast to adults where a standard grading system exists and is widely utilized across studies.

ERCP is a technically demanding procedure compared to an upper or lower GI endoscopy. Additionally, the potential for complications is higher and therefore, careful patient selection is paramount. With the availability of excellent non-invasive imaging modalities such as magnetic resonance
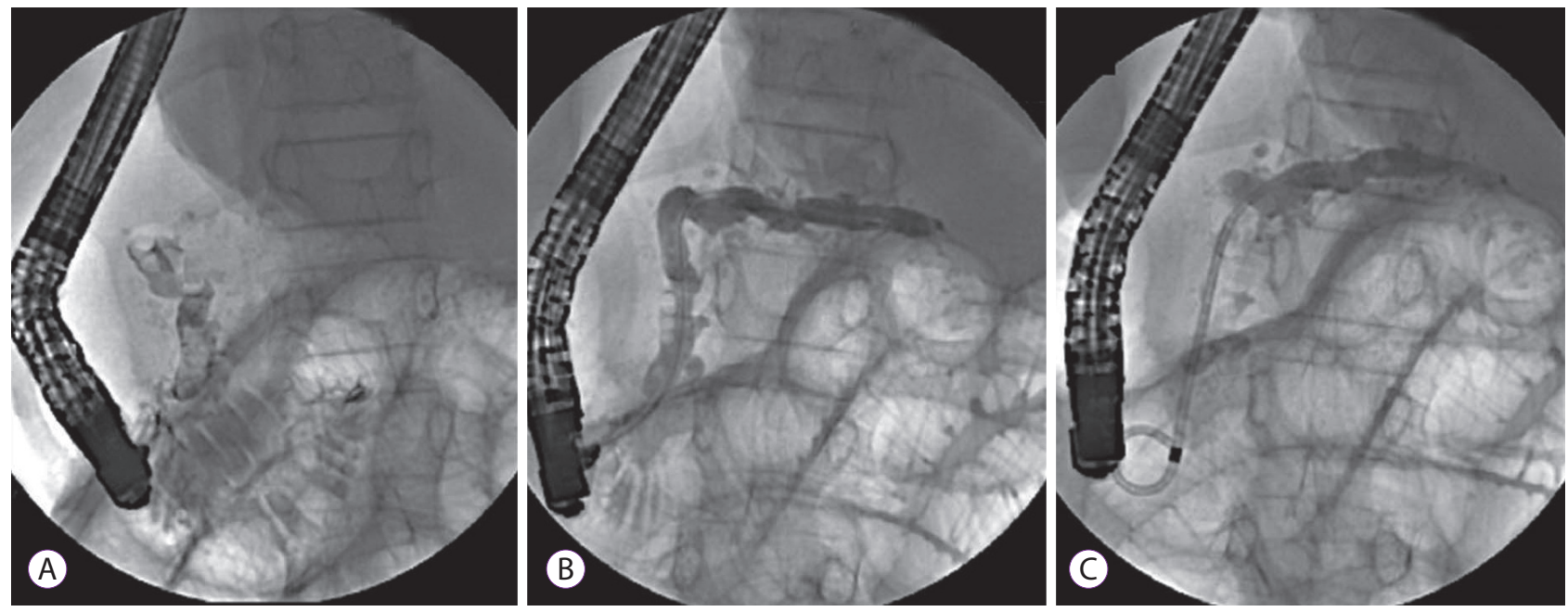

Fig. 1. Endotherapy for chronic pancreatitis in children. (A) Endoscopic retrograde pancreatography (ERP) revealing large intraductal calculi in the pancreatic head (note the limited opacification of the pancreatic duct due to the calculi). (B) ERP image obtained in the same child after undergoing extracorporeal shockwave lithotripsy (note the complete fragmentation of calculi with complete opacification of the pancreatic duct). (C) Placement of a 7 Fr single pigtail plastic stent into the pancreatic duct. 
cholangiopancreatography (MRCP), a therapeutic ERCP is preferred over a diagnostic procedure and is commonly performed to minimize the associated complications.

\section{ENDOSCOPIC ULTRASONOGRAPHY IN CHILDREN}

EUS is being increasingly used for both diagnostic and therapeutic indications. Emerging data suggests excellent safety and efficacy of EUS in the pediatric age group (Table 2). ${ }^{19-26}$ EUS has been utilized in children predominantly for diagnostic indications in various pancreatico-biliary disorders. This is in contrast to adults in whom EUS is being increasingly used as a therapeutic modality. Indications of a diagnostic EUS in children include evaluation of idiopathic recurrent pancreatitis, tissue sampling or pancreatic cyst aspiration for analysis, suspected choledocholithiasis, submucosal lesions (esophageal, gastric, rectal), and congenital disorders (esophageal stenosis, tracheobronchial remnants, duodenal duplication cysts). ${ }^{27-29}$ EUS has also been used for assessing portal hypertension and performing a liver biopsy when required. ${ }^{30}$

The advantages of EUS include a high axial resolution for accurate evaluation of the pancreatico-biliary system and the ability to sample the lesion (fine-needle aspiration or core needle biopsy) when required. Therefore, EUS scores over other imaging modalities like MRCP, contrast computed tomogra- phy (CT) and transabdominal ultrasonography in situations where tissue sampling may be necessary. Moreover, an MRCP requires patient cooperation, transabdominal ultrasonography is associated with limitations in terms of not always facilitating visualization of the distal common bile duct, and contrast $\mathrm{CT}$ is associated with radiation exposure. EUS can confirm the presence or absence of choledocholithiasis and avoid unnecessary ERCPs. However, an ERCP can be performed at the same time using the same sedation after confirmation of common bile duct calculi. A recent study wherein EUS was performed in 20 children with suspected bile duct calculi, EUS confirmed the absence of calculi in 13 children in whom ERCP could be avoided. ${ }^{25}$

The therapeutic use of EUS in children is limited and includes drainage of PFC, biliary drainage, and performing a celiac plexus block. EUS-guided drainage of PFC is safe and efficacious in children and is associated with reduced morbidity compared to percutaneous and surgical drainage. The advantages of EUS-guided drainage compared to non-EUSguided endoscopic drainage include the fact that the optimal site for drainage can be chosen and intervening vessels can be avoided. Additionally, it facilitates effective drainage of non-bulging collections. ${ }^{31}$

Recently, Nabi et al. evaluated the long-term outcomes of EUS-guided drainage of PFCs in 30 children. ${ }^{32}$ This study involved EUS-guided placement of one or more cystogastric double pigtail plastic stents. EUS-guided drainage was

Table 2. Studies Describing the Utility of Endosonography in Children (Selected Large Studies)

\begin{tabular}{|c|c|c|c|c|c|}
\hline Study & $n$ & $\begin{array}{l}\text { Mean age } \\
\text { yr (range) }\end{array}$ & EUS scope used & Impact of EUS & $\begin{array}{l}\text { Sedation } \\
\text { IV/GA (\%) }\end{array}$ \\
\hline Roseau et al. $(1998)^{19}$ & 18 & $12(4-16)$ & $\begin{array}{l}\text { GF UM3 } \\
\text { GF UM20 }\end{array}$ & - & $100 /-$ \\
\hline Varadarajulu et al. $(2005)^{20}$ & 14 & $\begin{array}{c}13 \text { (median) } \\
(5-17)\end{array}$ & $\begin{array}{l}\text { GF UM } 130 \text { (radial) } \\
\text { UC-30P (linear) }\end{array}$ & $93 \%$ & $-/ 100$ \\
\hline Bjerring et al. $(2008)^{21}$ & 18 & $\begin{array}{c}12(\text { median }) \\
(0.5-15)\end{array}$ & $\begin{array}{l}\text { FG } 34 \text { UX, } \\
\text { FG } 38 \text { UX }\end{array}$ & $78 \%$ & $-/ 100$ \\
\hline Cohen et al. $(2008)^{22}$ & 32 & $12(1.5-18)$ & $\begin{array}{l}\text { 34-UA, } \\
\text { 12-MHz miniprobe }\end{array}$ & $44 \%$ & $56 / 38$ \\
\hline Attila et al. $(2009)^{23}$ & 38 & $13.5(3-17)$ & $\begin{array}{l}\text { GF-UM160 } \\
\text { GF-UC140P AL5; FG36UX }\end{array}$ & - & $32.5 / 67.5$ \\
\hline Al-Rashdan et al. $(2010)^{24}$ & 56 & $\begin{array}{l}16(4-18) \\
(\text { median })\end{array}$ & $\begin{array}{l}\text { GF-UM20/130/160 } \\
\text { Pentax 32-UA/36-UX } \\
\text { GF-UC30P/140P-AL5 }\end{array}$ & $86 \%$ & $79 / 17.3$ \\
\hline Scheers et al. $(2015)^{25}$ & 48 & $12(2-17)$ & $\begin{array}{l}\text { FGUX-36, EG3830UT; } \\
\text { radial mini probe }\end{array}$ & $98 \%$ & $14 / 86$ \\
\hline Mahajan et al. $(2016)^{26}$ & 121 & $15.2(3-18)$ & $\begin{array}{l}\text { GF-UE } 160 \\
\text { EG-3670 URK } \\
\text { GF-UCT } 140 \\
\text { EG-3870UTK }\end{array}$ & $35.5 \%$ & $65 / 35$ \\
\hline
\end{tabular}

EUS, endoscopic ultrasonography; IV, intravenous; GA, general anesthesia. 
successfully completed in 29 children $(96.7 \%$ technical success). All the drainage procedures were effectively carried out under deep sedation using an intravenous injection of propofol. Clinical success was achieved in 28/30 (93.3\%) children. Plastic stents were not removed in children with a disconnected pancreatic duct. Using this approach, only two recurrences of PFC were noticed at median follow-up of 829 days (range, 150-1,230 days). ${ }^{32} \mathrm{~A}$ few other small series of studies involving pediatric patients have also concluded that EUS-guided drainage of PFC in children is safe and associated with good outcomes. ${ }^{33-35}$ Plastic stents have a smaller caliber and may get clogged easily in cases of walledoff necrosis which have debris present inside. In such cases, specially designed metal stents have proven their 'mettle' with excellent results in multiple large series of studies performed in adults. ${ }^{36-39}$ The advantages of new dedicated metal stents include a wider lumen, which allows efficient drainage and endoscopic necrosectomy. These stents are fully covered, which prevents tissue in-growth and allows easy removal. Moreover, these stents are either bi-flanged (Nagi stent; Taewoong Medical Co, Goyang, Korea) or have lumen-apposing properties (Axios stent; Xlumena, Mountain View, CA, USA) that help to reduce migration rates. ${ }^{36}$ More recently, the use of novel self-expanding metal stents has also been described in children with walled-off necrosis (Fig. 2). ${ }^{40,41}$
In a retrospective study, 21 children (mean age, $14.9+/-$ 2.34 years, 9-18 years) with walled-off necrosis underwent EUS-guided drainage using metal stents. The technical and clinical success rates were observed to be $100 \%$ and $95 \%$, respectively. ${ }^{41}$ None of the children enrolled in this study required endoscopic necrosectomy. In a few other case reports, necrosectomy has been reported in children with walled-off necrosis. ${ }^{42,43}$

The safety of EUS-guided drainage has been established in adults and major adverse events are uncommon. However, data are limited in children and a greater number of studies are required to establish the safety of endoscopic drainage of PFC in the pediatric population. Major complications that have been described include bleeding, perforation, and infection. A recent study performed in a pediatric population reported three major adverse events noticed during endoscopic drainage of PFC. These included occurrence of bleeding requiring arterial embolization in one and perforation in two children of which one required surgery (cystogastrostomy). ${ }^{32}$ Therefore, it is important that endoscopic drainage procedures in children should be performed by experts at well-equipped centers with availability of a multidisciplinary team including surgeons and interventional radiologists for timely intervention in cases of emergencies.
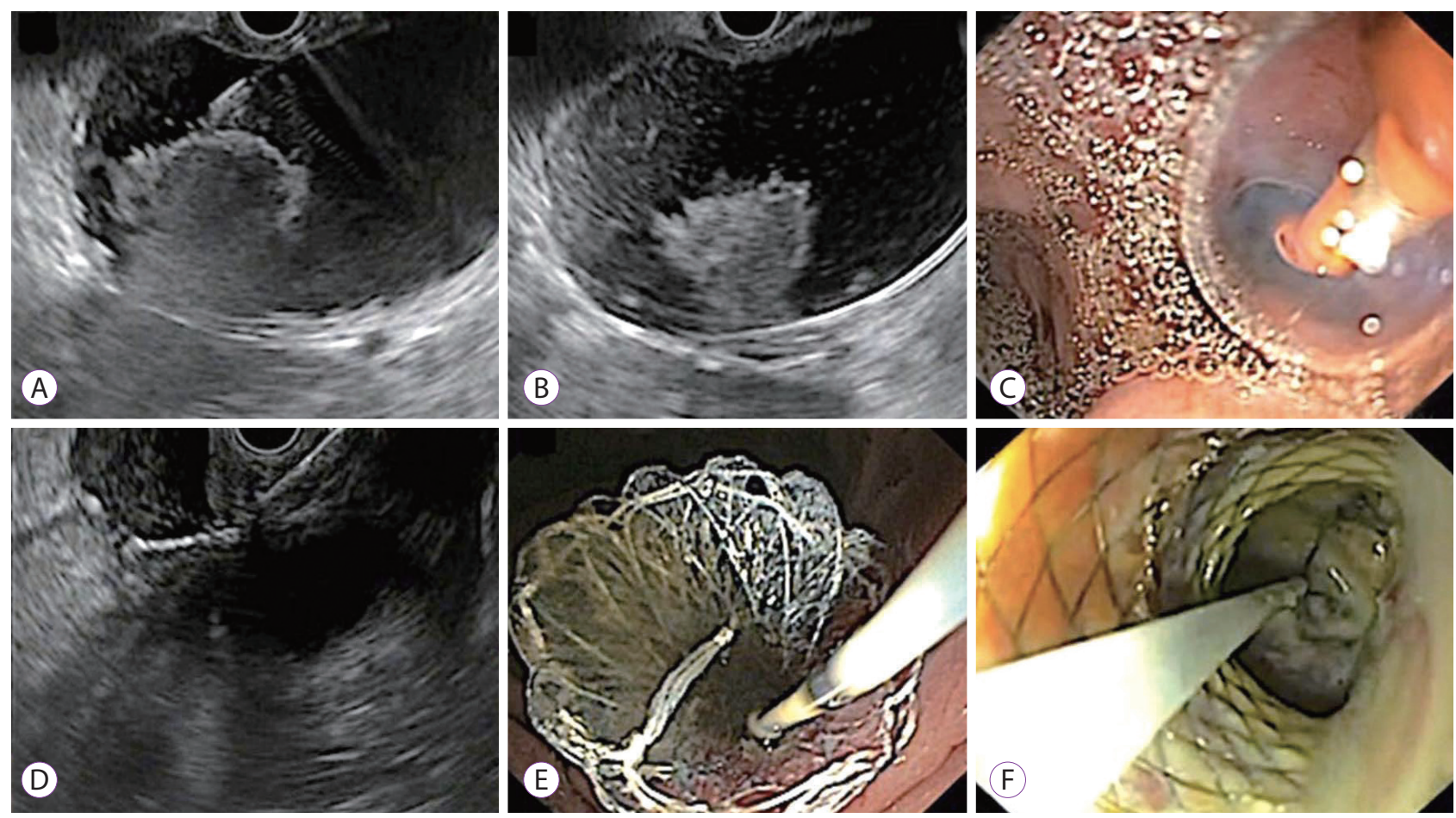

Fig. 2. Endoscopic ultrasound-guided drainage of walled-off necrosis in a child. (A) Puncture of cystogastric wall using a $21 \mathrm{G}$ fine-needle aspiration needle. (B) Coiling of the guide wire into the cyst cavity. (C) Balloon dilatation of the cystogastric tract. (D) Deployment of novel cystogastric metal stent. (E) Endoscopic view of the cystogastric metal stent. (F) Endoscopic necrosectomy in a child with walled-off necrosis. 
Table 3. Studies Depicting the Outcomes of Per-Oral Endoscopic Myotomy in Children

\begin{tabular}{lcclcc}
\hline Study & $\boldsymbol{n}$ & $\begin{array}{c}\text { Mean age } \\
\text { yr (range) }\end{array}$ & Complications & Clinical success & Follow up (mo) \\
\hline Nabi et al. $(2016)^{45}$ & 15 & $\begin{array}{c}14 \text { (median) } \\
(9-18)\end{array}$ & $33.3 \%$ (all minor) & $100 \%$ & up to 20 \\
\hline Chen et al. $(2015)^{49}$ & 27 & $13.8(6-17)$ & $\begin{array}{l}\text { Gas related }-63 \% \\
\text { Mucosal injury }-19.2 \%\end{array}$ & $96.3 \%$ & $15-38$ \\
\hline Li et al. $(2015)^{50}$ & 9 & $(10-17)$ & $22.2 \%$ (minor) & $100 \%$ & $3-30$ \\
Nabi et al. $(2018)^{51}$ & 10 & $14.2(9-18)$ & $40 \%$ (all minor) & $39-255$ (days) \\
Caldaro et al. $(2015)^{54}$ & 9 & $12.2(6-17)$ & $22.2 \%$ (minor) & $100 \%$ & $5-28$ \\
\hline
\end{tabular}
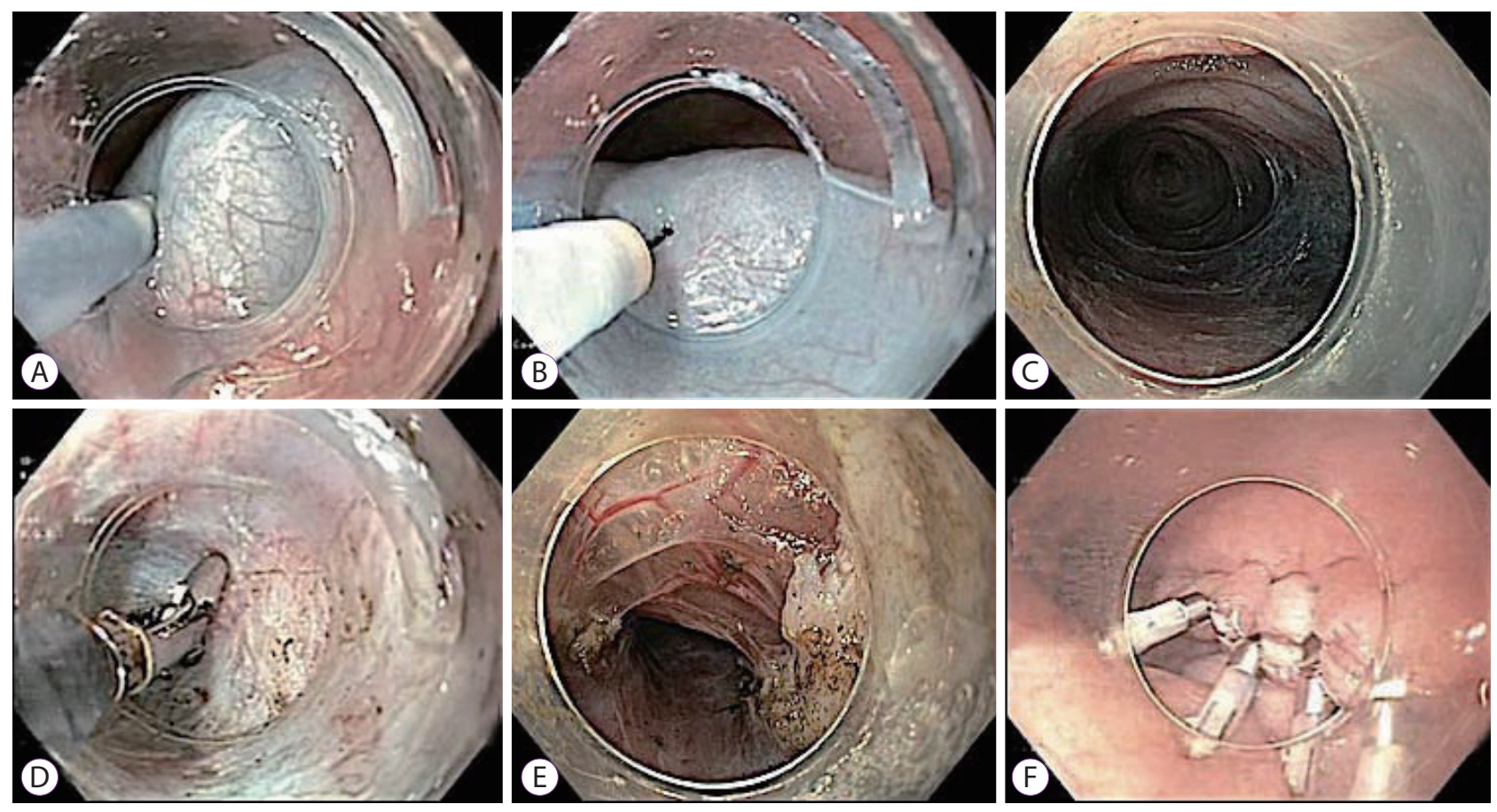

Fig. 3. Per-oral endoscopic myotomy in a child diagnosed with achalasia cardia. (A) Submucosal injection of dye solution to raise a bleb. (B) Mucosal incision over the bleb using a triangle tip knife. (C) Creation of a submucosal tunnel. (D) Coagulation of a vessel using coagulation forceps. (E) Full-thickness myotomy using a triangle tip knife. (F) Closure of the mucosal incision using hemostatic clips.

\section{PER-ORAL ENDOSCOPIC MYOTOMY IN CHILDREN}

$\mathrm{AC}$ is a rare neurodegenerative disorder resulting in aperistalsis and defective lower esophageal sphincter (LES) relaxation, ${ }^{44}$ showing an incidence of $0.1-0.18 / 10^{5}$ population/ year in the pediatric age group. ${ }^{45}$ The mainstay of endoscopic management is pneumatic balloon dilatation. However, the response after balloon dilatation is often short lived and repeated sessions of dilatation are frequently required.

Per-oral endoscopic myotomy (POEM) has evolved as an outstanding endoscopic treatment modality for the management of AC. Multiple large case series have established the safety and efficacy of POEM in adults diagnosed with AC. ${ }^{46,47}$
Data in children is limited to small case series and case reports. ${ }^{45,48-50}$ Nevertheless, the outcome of POEM in these case series is encouraging (Table 3).

Existing literature suggests that the procedure can be safely performed in an endoscopy suite in adults as well as in children. ${ }^{51,52}$ Equipment and accessories required for POEM include a gastroscope equipped with a water jet, a tapered tip transparent cap fitted on the distal end of the scope, an electrosurgical unit, a carbon dioxide $\left(\mathrm{CO}_{2}\right)$ insufflator, a low flow gas tube, coagulation forceps, an electrosurgical knife, and endoscopic clips.

POEM is performed under general anesthesia with the patient in a supine position. The technique of POEM involves a series of steps: (1) mucosal injection to raise a bleb, (2) mu- 
cosal incision using a needle knife, (3) submucosal tunneling using an electrosurgical knife (triangular or hybrid knife), (4) myotomy using the same knives, and (5) closure of the mucosal incision using endoclips (Fig. 3). Authors have previously described this procedure in detail in a video format. ${ }^{53}$

The clinical success rate of POEM in pediatric patients presenting with achalasia ranges from $90 \%-100 \%$ (Table 3). ${ }^{45,49-51,54}$ In a retrospective study, Nabi et al. evaluated the outcomes of POEM in 15 children with AC. ${ }^{45}$ Significant improvement was noticed in mean LES pressures $(36.64 \pm 11.08 \mathrm{~mm} \mathrm{Hg}$ vs. $15.65 \pm 5.73$ $\mathrm{mm} \mathrm{Hg})$, Eckardt scores (7.32 \pm 1.42 and 1.74 \pm 0.67$)$ and barium emptying after POEM. ${ }^{45}$ Unfortunately, no long-term follow-up study has been performed in children in contrast to adults diagnosed with AC. A study performed with a relatively long-term follow-up (24.6 months, range, 15-38 months) has reported clinical success in all children evaluated. ${ }^{49}$

POEM is a safe procedure when performed by experts. Most complications are minor in nature and can be easily managed intraoperatively. Adverse events associated with POEM include insufflations-related complications (capnoperitoneum, capnothorax, capnomediastinum), mucosal injuries, and bleeding. The incidence of insufflation-related adverse events is higher if air is used for insufflation instead of $\mathrm{CO}_{2}$ because the latter has a higher diffusion capacity. A prospective study has reported that the incidence of gas-related adverse events was significantly higher with use of air compared to $\mathrm{CO}_{2}(84.6 \%$ vs. $16.7 \%, p<0.04){ }^{49}$

With innovations in the development of new devices and techniques, the procedure may become easier and less time consuming. A recent study evaluated the efficacy of a new triangular tip knife equipped with a water jet function in pediatric patients. Authors concluded that the procedure was technically easier, and the time required to complete the procedure was shorter than that observed in the conventional triangular knife group. ${ }^{51}$

Based on the available data, it can be concluded that POEM is a promising treatment modality that can be used in pediatric patients, although further prospective studies with a larger sample size are required to conclusively establish its usefulness. Additionally, comparative studies with established treatment modalities such as Heller's myotomy and pneumatic balloon dilatation are essential to conclusively establish the role of POEM in pediatric patients presenting with AC.

\section{CONCLUSIONS}

The horizon of therapeutic GI endoscopy in children is now expanding. Because most procedures have been adapted from adults, devices and accessories have not been designed specifically for use in children. For this same reason, a large proportion of advanced endoscopic procedures in the pediatric age group continue to be performed by gastroenterologists operating in the adult domain. The size of adult scopes may be disproportionate for smaller airways in children and demand general anesthesia in a large proportion of cases compared to adults. The indications of advanced endoscopic procedures are different and fewer in children compared to adults, thereby explaining the slow development of the same in children. Newer devices suitable for pediatric use are required. It seems prudent to propose that a formal training program should be introduced to train pediatric gastroenterologists in these procedures. Until then pediatric and adult gastroenterologists can work in collaboration to optimize the outcomes of advanced endoscopic procedures performed in children.

\section{Conflicts of Interest}

The authors have no financial conflicts of interest.

\section{REFERENCES}

1. ASGE Standards of Practice Committee, Lightdale JR, Acosta R, et al. Modifications in endoscopic practice for pediatric patients. Gastrointest Endosc 2014;79:699-710.

2. Thomson M, Tringali A, Dumonceau JM, et al. Paediatric gastrointestinal endoscopy: European society for paediatric gastroenterology hepatology and nutrition and European society of gastrointestinal endoscopy guidelines. J Pediatr Gastroenterol Nutr 2017;64:133-153.

3. Tringali A, Thomson M, Dumonceau JM, et al. Pediatric gastrointestinal endoscopy: European society of gastrointestinal endoscopy (ESGE) and European society for paediatric gastroenterology hepatology and nutrition (ESPGHAN) guideline executive summary. Endoscopy 2017;49:8391.

4. Varadarajulu S, Wilcox CM, Hawes RH, Cotton PB. Technical outcomes and complications of ERCP in children. Gastrointest Endosc 2004;60:367-371.

5. Cheng CL, Fogel EL, Sherman S, et al. Diagnostic and therapeutic endoscopic retrograde cholangiopancreatography in children: a large series report. J Pediatr Gastroenterol Nutr 2005;41:445-453.

6. Issa $\mathrm{H}, \mathrm{Al}$-Haddad $\mathrm{A}, \mathrm{Al}$-Salem $\mathrm{AH}$. Diagnostic and therapeutic ERCP in the pediatric age group. Pediatr Surg Int 2007;23:111-116.

7. Dua K, Miranda A, Santharam R, Ramanujam S, Werlin S. ERCP in the evaluation of abdominal pain in children. Gastrointest Endosc 2008;68:1081-1085.

8. Otto AK, Neal MD, Slivka AN, Kane TD. An appraisal of endoscopic retrograde cholangiopancreatography (ERCP) for pancreaticobiliary disease in children: our institutional experience in 231 cases. Surg Endosc 2011;25:2536-2540.

9. Enestvedt BK, Tofani C, Lee DY, et al. Endoscopic retrograde cholangiopancreatography in the pediatric population is safe and efficacious. J Pediatr Gastroenterol Nutr 2013;57:649-654

10. Agarwal J, Nageshwar Reddy D, Talukdar R, et al. ERCP in the management of pancreatic diseases in children. Gastrointest Endosc 2014;79:271-278.

11. Saito T, Terui K, Mitsunaga T, et al. Role of pediatric endoscopic retrograde cholangiopancreatography in an era stressing less-invasive imag- 
ing modalities. J Pediatr Gastroenterol Nutr 2014;59:204-209.

12. Giefer MJ, Kozarek RA. Technical outcomes and complications of pediatric ERCP. Surg Endosc 2015;29:3543-3550.

13. Rosen JD, Lane RS, Martinez JM, et al. Success and safety of endoscopic retrograde cholangiopancreatography in children. J Pediatr Surg 2017;52:1148-1151.

14. Oracz G, Pertkiewicz J, Dadalski M, et al. Complications of endoscopic retrograde cholangiopancreatography in children with chronic pancreatitis depends on center experience. J Pediatr 2017;186:215-216.

15. Wang D, Bi YW, Ji JT, et al. Extracorporeal shock wave lithotripsy is safe and effective for pediatric patients with chronic pancreatitis. Endoscopy 2017;49:447-455.

16. Cho JM, Jeong IS, Kim HJ, Oh SH, Kim KM. Early adverse events and long-term outcomes of endoscopic sphincterotomy in a pediatric population: a single-center experience. Endoscopy 2017;49:438-446.

17. Usatin D, Fernandes M, Allen IE, Perito ER, Ostroff J, Heyman MB. Complications of endoscopic retrograde cholangiopancreatography in pediatric patients; a systematic literature review and meta-analysis. J Pediatr 2016;179:160-165.e3.

18. Troendle DM, Abraham O, Huang R, Barth BA. Factors associated with post-ERCP pancreatitis and the effect of pancreatic duct stenting in a pediatric population. Gastrointest Endosc 2015;81:1408-1416.

19. Roseau G, Palazzo L, Dumontier I, et al. Endoscopic ultrasonography in the evaluation of pediatric digestive diseases: preliminary results. Endoscopy 1998;30:477-481.

20. Varadarajulu S, Wilcox CM, Eloubeidi MA. Impact of EUS in the evaluation of pancreaticobiliary disorders in children. Gastrointest Endosc 2005;62:239-244.

21. Bjerring OS, Durup J, Qvist N, Mortensen MB. Impact of upper gastrointestinal endoscopic ultrasound in children. J Pediatr Gastroenterol Nutr 2008;47:110-113.

22. Cohen S, Kalinin M, Yaron A, Givony S, Reif S, Santo E. Endoscopic ultrasonography in pediatric patients with gastrointestinal disorders. J Pediatr Gastroenterol Nutr 2008;46:551-554.

23. Attila T, Adler DG, Hilden K, Faigel DO. EUS in pediatric patients. Gastrointest Endosc 2009;70:892-898.

24. Al-Rashdan A, LeBlanc J, Sherman S, McHenry L, DeWitt J, Al-Haddad M. Role of endoscopic ultrasound for evaluating gastrointestinal tract disorders in pediatrics: a tertiary care center experience. J Pediatr Gastroenterol Nutr 2010;51:718-722.

25. Scheers I, Ergun M, Aouattah T, et al. Diagnostic and therapeutic roles of endoscopic ultrasound in pediatric pancreaticobiliary disorders. J Pediatr Gastroenterol Nutr 2015;61:238-247.

26. Mahajan R, Simon EG, Chacko A, et al. Endoscopic ultrasonography in pediatric patients--experience from a tertiary care center in India. Indian J Gastroenterol 2016;35:14-19.

27. Gordon K, Conway J, Evans J, Petty J, Fortunato JE, Mishra G. EUS and EUS-guided interventions alter clinical management in children with digestive diseases. J Pediatr Gastroenterol Nutr 2016;63:242-246.

28. Patel S, Marshak J, Daum F, Iqbal S. The emerging role of endoscopic ultrasound for pancreaticobiliary diseases in the pediatric population. World J Pediatr 2017;13:300-306.

29. Lakhole A, Liu QY. Role of endoscopic ultrasound in pediatric disease. Gastrointest Endosc Clin N Am 2016;26:137-153.

30. Johal AS, Khara HS, Maksimak MG, Diehl DL. Endoscopic ultrasound-guided liver biopsy in pediatric patients. Endosc Ultrasound 2014;3:191-194.

31. Nabi Z, Talukdar R, Reddy DN. Endoscopic management of pancreatic fluid collections in children. Gut Liver 2017;11:474-480.

32. Nabi Z, Lakhtakia S, Basha J, et al. Endoscopic drainage of pancreatic fluid collections: long-term outcomes in children. Dig Endosc 2017;29:790-797.

33. Lakhtakia S, Agarwal J, Gupta R, Ramchandani M, Kalapala R, Nagesh- war Reddy D. EUS-guided transesophageal drainage of peripancreatic fluid collections in children. Gastrointest Endosc 2015;82:587-588.

34. Ramesh J, Bang JY, Trevino J, Varadarajulu S. Endoscopic ultrasound-guided drainage of pancreatic fluid collections in children. J Pediatr Gastroenterol Nutr 2013;56:30-35.

35. Jazrawi SF, Barth BA, Sreenarasimhaiah J. Efficacy of endoscopic ultrasound-guided drainage of pancreatic pseudocysts in a pediatric population. Dig Dis Sci 2011;56:902-908.

36. Nabi Z, Basha J, Reddy DN. Endoscopic management of pancreatic fluid collections-revisited. World J Gastroenterol 2017;23:2660-2672.

37. Siddiqui AA, Adler DG, Nieto J, et al. EUS-guided drainage of peripancreatic fluid collections and necrosis by using a novel lumen-apposing stent: a large retrospective, multicenter U.S. experience (with videos). Gastrointest Endosc 2016;83:699-707.

38. Rinninella E, Kunda R, Dollhopf M, et al. EUS-guided drainage of pancreatic fluid collections using a novel lumen-apposing metal stent on an electrocautery-enhanced delivery system: a large retrospective study (with video). Gastrointest Endosc 2015;82:1039-1046.

39. Sharaiha RZ, Tyberg A, Khashab MA, et al. Endoscopic therapy with lumen-apposing metal stents is safe and effective for patients with pancreatic walled-off necrosis. Clin Gastroenterol Hepatol 2016;14:17971803.

40. Bang JY, Varadarajulu S. Endoscopic treatment of walled-off necrosis in children: clinical experience and treatment outcomes. J Pediatr Gastroenterol Nutr 2016;63:e31-e35.

41. Nabi Z, Lakhtakia S, Basha J, et al. Endoscopic ultrasound-guided drainage of walled-off necrosis in children with fully covered self-expanding metal stents. J Pediatr Gastroenterol Nutr 2017;64:592-597.

42. Trikudanathan G, Arain M, Mallery S, Freeman M, Attam R. Endoscopic necrosectomy in children. J Pediatr Gastroenterol Nutr 2014;59:270273.

43. Kheder J, Han S, Wassef WY. Successful endoscopic pancreatic necrosectomy in 5-year-old child. Am J Gastroenterol 2016;111:443-444.

44. Nabi Z, Reddy DN. Achalasia cardia-recent advances in diagnosis and endoscopic management. J Gastrointest Dig Syst 2016;6:393.

45. Nabi Z, Ramchandani M, Reddy DN, et al. Per oral endoscopic myotomy in children with achalasia cardia. J Neurogastroenterol Motil 2016;22:613-619.

46. Nabi Z, Ramchandani M, Chavan R, et al. Per-oral endoscopic myotomy for achalasia cardia: outcomes in over 400 consecutive patients. Endosc Int Open 2017;5:E331-E339.

47. Inoue $\mathrm{H}$, Sato $\mathrm{H}$, Ikeda $\mathrm{H}$, et al. Per-oral endoscopic myotomy: a series of 500 patients. J Am Coll Surg 2015;221:256-264.

48. Tan Y, Zhu H, Li C, Chu Y, Huo J, Liu D. Comparison of peroral endoscopic myotomy and endoscopic balloon dilation for primary treatment of pediatric achalasia. J Pediatr Surg 2016;51:1613-1618.

49. Chen WF, Li QL, Zhou PH, et al. Long-term outcomes of peroral endoscopic myotomy for achalasia in pediatric patients: a prospective, single-center study. Gastrointest Endosc 2015;81:91-100.

50. Li C, Tan Y, Wang X, Liu D. Peroral endoscopic myotomy for treatment of achalasia in children and adolescents. J Pediatr Surg 2015;50:201-205.

51. Nabi Z, Ramchandani M, Chavan R, et al. Peroral endoscopic myotomy in children: first experience with a new triangular knife. J Pediatr Gastroenterol Nutr 2018;66:43-47.

52. Khashab MA, El Zein M, Kumbhari V, et al. Comprehensive analysis of efficacy and safety of peroral endoscopic myotomy performed by a gastroenterologist in the endoscopy unit: a single-center experience. Gastrointest Endosc 2016;83:117-125.

53. Nabi Z, Ramchandani M, Reddy DN. Peroral endoscopic myotomy in a child with achalasia cardia. J Pediatr Gastroenterol Nutr 2017;65:e44.

54. Caldaro T, Familiari P, Romeo EF, et al. Treatment of esophageal achalasia in children: today and tomorrow. J Pediatr Surg 2015;50:726-730. 